BNL-95100-2011-CP

\title{
Seismic Analysis Issues on Design Certification Applications for New Reactors
}

\author{
Manuel Miranda, Richard Morante, Jim Xu \\ Presented at the ASME 2011 Pressure Vessels \& Piping Division Conference \\ Baltimore, $\mathrm{MD}$ \\ July 17-21, 2011
}

\author{
Nuclear Science and Technology Department \\ Brookhaven National Laboratory
}

Nuclear Regulatory Commission

Notice: This manuscript has been authored by employees of Brookhaven Science Associates, LLC under Contract No. DE-AC02-98CH10886 with the U.S. Department of Energy. The publisher by accepting the manuscript for publication acknowledges that the United States Government retains a non-exclusive, paid-up, irrevocable, world-wide license to publish or reproduce the published form of this manuscript, or allow others to do so, for United States Government purposes. 


\section{DISCLAIMER}

This report was prepared as an account of work sponsored by an agency of the United States Government. Neither the United States Government nor any agency thereof, nor any of their employees, nor any of their contractors, subcontractors, or their employees, makes any warranty, express or implied, or assumes any legal liability or responsibility for the accuracy, completeness, or any third party's use or the results of such use of any information, apparatus, product, or process disclosed, or represents that its use would not infringe privately owned rights. Reference herein to any specific commercial product, process, or service by trade name, trademark, manufacturer, or otherwise, does not necessarily constitute or imply its endorsement, recommendation, or favoring by the United States Government or any agency thereof or its contractors or subcontractors. The views and opinions of authors expressed herein do not necessarily state or reflect those of the United States Government or any agency thereof. 


\section{Proceedings of the ASME 2011 Pressure Vessels \& Piping Division Conference PVP2011 \\ July 17-21, 2011, Baltimore, Maryland, USA}

PVP2011-57667

\section{SEISMIC ANALYSIS ISSUES IN DESIGN CERTIFICATION APPLICATIONS FOR NEW REACTORS}

\author{
Richard Morante \\ Manuel Miranda \\ Nuclear Science and Technology Department \\ Brookhaven National Laboratory \\ Upton, New York 11973-5000 \\ Email: mmiranda@bnl.gov
}

\author{
$\operatorname{Jim} \mathbf{X u}$ \\ Office of New Reactors \\ U.S. Nuclear Regulatory Commission \\ Washington, DC 20545-0001
}

\begin{abstract}
The licensing framework established by the U.S. Nuclear Regulatory Commission under Title 10 of the Code of Federal Regulations (10 CFR) Part 52, "Licenses, Certifications, and Approvals for Nuclear Power Plants," provides requirements for standard design certifications (DCs) and combined license (COL) applications. The intent of this process is the early resolution of safety issues at the DC application stage. Subsequent COL applications may incorporate a DC by reference. Thus, the COL review will not reconsider safety issues resolved during the DC process. However, a COL application that incorporates a $D C$ by reference must demonstrate that relevant site-specific design parameters are within the bounds postulated by the DC, and any departures from the DC need to be justified.

This paper provides an overview of several seismic analysis issues encountered during a review of recent DC applications under the 10 CFR Part 52 process, in which the authors have participated as part of the safety review effort.
\end{abstract}

\section{INTRODUCTION}

For the current fleet of nuclear power plants (NPPs), the U.S. Nuclear Regulatory Commission (NRC) issued operating licenses after plant construction was completed, under the licens-

This material is declared a work of the U.S. Government and is not subject to copyright protection in the United States. Approved for public release; distribution is unlimited. ing framework established by Title 10 of the Code of Federal Regulations (10 CFR) Part 50, "Domestic Licensing of Production and Utilization Facilities" [1]. Therefore, the seismic analysis of NPP structures, systems, and components (SSCs) was performed using site-specific design parameters based on actual site investigations. The SSC analysis and design typically followed the acceptance criteria of NUREG-0800, "Standard Review Plan for the Review of Safety Analysis Reports for Nuclear Power Plants: LWR Edition" (SRP) [2], which provides guidance to the NRC staff for performing its safety reviews.

For new reactors, the licensing framework established under 10 CFR Part 52, "Licenses, Certifications, and Approvals for Nuclear Power Plants" [3], provides requirements for standard design certifications (DCs) and combined license (COL) applications. The intent of this process is the early resolution of safety issues at the DC application stage. Subsequent COL applications may incorporate a DC by reference. Thus, the COL review will not reconsider safety issues resolved during the $\mathrm{DC}$ process. However, a COL application that incorporates a DC by reference must demonstrate that relevant site-specific design parameters are confined within the bounds postulated by the DC, and any departures from the DC need to be justified.

In a DC application, the seismic analysis of SSCs must establish design bounds for future potential sites. Therefore, seismic ground motions and other site parameters (e.g., soil profiles and associated soil characteristics) are conservatively specified, representing envelopes of site-specific seismic hazards and other 
parameters expected at potential sites. If a COL application incorporates a DC by reference, it needs to demonstrate that the site-specific ground motion response spectrum (GMRS) and the site-specific soil profile are enveloped by the certified seismic design response spectra (CSDRS) and generic soil profiles for which the design has been certified. The COL application should also demonstrate that other site parameters (e.g., soil bearing capacity) are within the bounds established by the DC. Numerous challenges in establishing the seismic design basis of SSCs at both the DC and COL application stages were identified. This paper presents some examples of these challenges and lessons learned. It is hoped that a better understanding of these issues will contribute to the improvement of future DC and COL applications and also facilitate NRC safety reviews. The reader is also referred to a previous paper by $\mathrm{Xu}$ and Samaddar [4], which provides additional discussions of these topics.

\section{BACKGROUND}

Until the 1970s, the seismic analysis and design of NPPs was based on the concept of "safe-shutdown earthquake" (SSE), which is defined in Appendix S, "Earthquake Engineering Criteria for Nuclear Power Plants," to 10 CFR Part 50 and Appendix A, "Seismic and Geologic Siting Criteria for Nuclear Power Plants," to 10 CFR Part 100, "Reactor Site Criteria" [5], as the vibratory ground motion for which safety-related SSCs must be designed to remain functional and within applicable stress, strain, and deformation limits. The NRC subsequently published a series of regulatory guides (RGs) in support of 10 CFR Part 50, Appendix S, and 10 CFR Part 100, Appendix A, including RG 1.60, "Design Response Spectra for Seismic Design of Nuclear Power Plants" [6]. The seismic analysis process for NPPs thus required site-specific investigations involving seismology, geology, and geotechnical engineering that were used to estimate a site-specific, hazard-based, peak ground acceleration (PGA). The site-specific SSE was then specified in terms of broadband smooth response spectra, analogous to the RG 1.60 spectra, anchored to the PGA and defined at the ground surface in the free field. The corresponding seismic analysis and design of safetyrelated SSCs typically followed the acceptance criteria of the SRP, which provides guidance to the NRC staff for performing its safety reviews.

To address the seismic issues associated with the $10 \mathrm{CFR}$ Part 52 licensing process, pertaining to the seismic analysis and design of new NPPs, the nuclear industry initiated the New Reactor Seismic Issues Resolution Program to coordinate its effort with the NRC. The program addressed two critical issues: (1) the implementation of a performance-based approach for developing site-specific ground motions and (2) an evaluation methodology for considering the effects of high-frequency ground motions.

The NRC has implemented the performance-based approach for developing site-specific ground motions through the publica- tion of RG 1.208, "A Performance-Based Approach to Define the Site-Specific Earthquake Ground Motion" [7], which provides a method for developing risk-consistent site-specific ground motions based on a probabilistic seismic hazard analysis (PSHA). The performance-based approach with a stipulated target performance goal is consistent with the risk goals described in the NRC's policy statement for the operation of NPPs.

To address the high-frequency seismic issues in DC and COL applications, the NRC developed Interim Staff Guidance (ISG)-01, "Interim Staff Guidance on Seismic Issues Associated with High Frequency Ground Motion," issued 2009 [8], which describes an acceptable process for assessing the effect of highfrequency ground motion on the seismic design of new NPPs. ISG-01 supplements the guidance provided in SRP Section 3.7.1, “Seismic Design Parameters," Revision 3.

\section{SEISMIC ANALYSIS ISSUES}

The authors have selected the following topics that are important to establish the seismic design basis for a certified design:

1. definition of the CSDRS

2. specification of generic site conditions for design certification

3. soil-structure interaction (SSI) analysis methods

4. seismic model refinement to capture all vibration modes of interest

5. treatment of concrete stiffness in seismic analysis models

The authors note that this is not an inclusive list of all potentially significant topics. It represents specific topics for which the authors have first-hand experience. Additional topics are discussed by Xu and Samaddar [4].

\section{Certified Seismic Design Response Spectra}

The CSDRS is part of the site parameters postulated by the DC applicant for seismic analysis and design. To ensure the applicability of the certified design to the broadest range of potential sites, the applicant typically selects a CSDRS of sufficient magnitude to ensure a robust seismic design. Recent DC applicants have specified a RG 1.60 spectral shape anchored at a $0.3 \mathrm{~g}$ PGA or a close approximation to it. While this definition for the CSDRS imposes a very significant seismic demand, the amplified frequency region of the RG 1.60 spectral shape does not envelope the hard rock high-frequency (HRHF) spectra for certain central and eastern United States (CEUS) sites. To ensure the seismic design adequacy of certified designs for HRHF spectra, recent DC applications considered several approaches, as described below.

Approach 1 The DC applicant defined its CSDRS as an envelope of RG 1.60 spectra anchored at $0.3 \mathrm{~g}$ PGA and representative 
HRHF spectra that enveloped all potential candidate CEUS sites at the time of submittal of the DC application. The HRHF spectra define the CSDRS envelope above $10 \mathrm{~Hz}$. Below $10 \mathrm{~Hz}$, the RG 1.60 spectra define the CSDRS envelope. The applicant defined synthetic time histories to match the CSDRS envelope and analyzed all assumed generic soil profiles using this input. The seismic analyses did not take credit for the potential reduction of the effective HRHF demand due to incoherency effects. This approach imposed a conservative seismic demand, compared to a site-specific seismic demand. A COL applicant would demonstrate that site-specific GMRS are enveloped by the CSDRS and that the site soil profile is bounded by the generic soil profiles analyzed for the CSDRS demand.

Approach 2 The DC applicant defined the CSDRS using a set of spectra. Response spectra similar to RG 1.60 spectra anchored at $0.3 \mathrm{~g}$ PGA but modified to account for soft, medium, and stiff soil conditions were selected, in conjunction with a set of HRHF spectra for CEUS sites, to establish the CSDRS for seismic analysis and design. The seismic analyses were then performed for each design spectra and associated generic soil profiles (ranging from soft and medium to stiff soil conditions, as well as rock conditions related to HRHF), using synthetic time histories matching the corresponding spectra. The seismic analyses did not take credit for the potential reduction of the effective HRHF demand due to incoherency effects. With this approach, structural design and specification of in-structure response spectra (ISRS) satisfy the seismic demands established from all analyses involving the CSDRS and associated generic soil profiles. A COL applicant would have to demonstrate that site-specific GMRS are enveloped completely by one of the CSDRS spectra and that the site soil profile is bounded by the generic site profile(s) associated with the selected CSDRS spectra.

Approach 3 The DC applicant defined its CSDRS as RG 1.60 spectra anchored at $0.3 \mathrm{~g}$ PGA, with an additional control point at $25 \mathrm{~Hz}$. The seismic analyses were then performed using synthetic time histories to match the CSDRS and assumed generic soil profiles. The envelope of the responses to these analyses was used for structural design and the generation of ISRS. The guidance in ISG-01 was used to demonstrate the adequacy of the design for representative HRHF spectra. ISG-01 allows for the potential reduction of effective HRHF demands due to incoherency effects. While it is not formally a part of the applicant's CSDRS, the applicant demonstrated that the defined HRHF spectra and site profile have been analyzed consistent with the guidance in ISG-01, to demonstrate structural design adequacy. A COL applicant would have to demonstrate that site-specific GMRS are enveloped completely, either by the CSDRS or by the representative HRHF spectra, and that the site soil profile is bounded by the applicable generic assumptions.

\section{Specification of Generic Site Conditions for Design Certification}

Once a DC applicant has defined the CSDRS, the next important consideration is selection of a representative set of generic site conditions for SSI analysis. The selection of the generic site conditions is made by considering the application of the DC to potential sites. To maximize the applicability of the certified design to the broadest range of potential sites, the applicant typically specifies a range from "soft soil" with a minimum shear wave velocity of $305 \mathrm{~m} / \mathrm{s}(1,000 \mathrm{ft} / \mathrm{s})$ to "hard rock" with a shear wave velocity of $2,440 \mathrm{~m} / \mathrm{s}(8,000 \mathrm{ft} / \mathrm{s})$ or higher. Between these bounds, there are theoretically an infinite number of site conditions that can be specified for SSI analysis. The objective is to define a reasonable number of generic site conditions (typically 10 or less) for SSI analysis, such that the envelope of responses will be directly applicable to a large number of potential sites without the need for COL applicants to perform a site-specific SSI analysis.

Based on recent DC application reviews, one significant issue potentially restricting the applicability of the generic results to specific sites is the consideration of horizontal, vertical, and sloping variations in the site-specific profile. The generic profiles typically assume horizontal uniformity and gradual (if any) vertical variation. Defining the maximum permissible site-specific deviation from the assumed generic profiles is an important determination. The definition of these limitations is added to the list of site parameters that a COL applicant should meet; otherwise, a site-specific SSI analysis is required.

\section{Soil-Structure Interaction Analysis Methods}

The current industry standard for conducting SSI analysis in the frequency domain is based on the substructuring method, as implemented in the SASSI computer code. Although the SASSI code was developed by researchers at the University of California, Berkeley, commercial versions of the code are typically used for SSI analyses of nuclear facilities. An important task of the safety review is to ensure that the DC applicant's version of the SASSI code is adequately benchmarked and up-to-date and that the implementing organization has adequate expertise and experience to perform the SSI analyses. As part of the safety review of the applicant's SSI analysis, it is common practice for the staff to perform its own confirmatory SASSI analysis to verify the applicant's results. In recent DC application reviews, the confirmatory analysis results have not always validated the applicant's results. Appropriate application of the SASSI code requires a unique set of skills and experience, including knowledge of wave propagation theory and its application to free-field modeling, site-response, and SSI analyses. Close scrutiny is often required to establish the acceptability of a SASSI SSI analysis.

In one DC application, the applicant presented results from an extensive series of SSI analyses in the time domain using 
frequency-independent soil springs - a conventional approach before the advent of the SASSI code. To demonstrate the conservatism of the time domain SSI analyses, a set of SASSI SSI analyses were also performed by the applicant; in parallel, the staff conducted an independent set of confirmatory SASSI SSI analyses, using the applicant's structural models. Comparisons of the time domain SSI analyses to the SASSI analyses indicated that the time domain SSI analyses, based on frequency-independent soil springs, significantly envelope both sets of SASSI results and, therefore, are conservative as seismic design basis analyses.

In another DC application, the staff's confirmatory SASSI analyses identified a modeling error in the applicant's original SASSI analyses. This necessitated SSI reanalyses by the applicant after the SASSI model was corrected. A detailed review of SSI analysis methods and results in conjunction with independent confirmatory analysis is essential and increases confidence in the acceptance of the resulting SSI results.

\section{Seismic Model Refinement}

The mathematical models of seismic Category I structures that are used for design-basis seismic analysis should have sufficient refinement to capture all vibration modes of interest. This is typically up to $33 \mathrm{~Hz}$ for spectra comparable to RG 1.60 spectra, and up to $50 \mathrm{~Hz}$ for HRHF spectra. The local (out-of-plane) flexibility of floors, walls, and ceilings may result in amplified local responses that need to be considered in structural design and in developing the ISRS for the seismic analysis of subsystems and components.

The local regions in need of refinement should be identified during the model development stage and considered by the analyst in the development of computationally efficient models for conducting multiple SSI analyses. Unfortunately, some versions of the SASSI code limit the maximum number of degrees of freedom in the overall model. The structural model of the nuclear island (i.e., all seismic Category I structures that share a common foundation) that meets the refinement requirements may be too large to analyze with the SASSI code. This potential limitation should be recognized in advance and an analysis plan developed to work around the limitation.

Recent DC applicants have recognized the need to consider local flexible regions and have included local model refinement in their seismic analysis models. However, the safety reviews have identified certain shortcomings in the treatment of this issue. In particular, the safety reviews identified flexible regions of Category I structures that were not included in the design-basis seismic analyses. This resulted in the need to perform additional design-basis seismic analyses to incorporate the effects of the omitted flexible regions.

Considerable review time was expended to look at structural details and modeling details and to perform a simplified, confirmatory, frequency and mode shape analysis, before the adequacy of the seismic analyses results could be properly assessed. Experience shows that a comprehensive discussion of this issue, and how it has been addressed in the design-basis seismic analyses, could facilitate the review of future DC applications.

\section{Treatment of Concrete Stiffness in Seismic Analysis Models}

It is well known that cracking can affect the seismic response of concrete structures in a significant manner. In general, concrete cracking reduces the stiffness of the structural elements and determines a corresponding reduction in the fundamental frequencies. Depending on the frequency content of the ground motion, this frequency shift can result in an increase or a decrease in seismic demands, although it is not always clear which is the case.

The severity and extent of concrete cracking depends on the state of stress of the structural elements for the various design load combinations. Therefore, cracking is not uniformly distributed throughout the structure but, rather, is most significant in the regions with the largest stress levels. The complexity of concrete cracking makes it impractical to realistically include these effects in the seismic analysis model. Industry standards such as American Society of Civil Engineers (ASCE) 4-98, "Seismic Analysis of Safety-Related Nuclear Structures and Commentary" [9] (see Section 3.1.3 and commentary), and ASCE 4305, "Seismic Design Criteria for Structures, Systems, and Components in Nuclear Facilities" [10] (see Section 3.4.1 and commentary), provide some guidance on how to modify the structural stiffness to account for the effects of concrete cracking, in a simplified manner, for different types of structural elements and different stress levels.

Recent DC applications have accounted for concrete cracking in a simplified manner by globally reducing the concrete modulus of elasticity of all structural elements by a certain amount. Two applicants determined seismic demands, including ISRS, as the envelope of demands calculated using a seismic analysis model with (1) the full value of the concrete modulus of elasticity and (2) a 50 percent reduced value of the concrete modulus of elasticity. As previously noted, it is not always clear whether the shift in frequencies due to cracking results in an increase or decrease of seismic demands; therefore, this type of bounding approach is preferred.

One applicant provided technical justification for using 80 percent of the concrete modulus of elasticity, based on a comparison of the linear analysis using the 80 percent value to the nonlinear analysis that incorporated concrete cracking. The staff compared the frequencies and response magnitudes and found the applicant's technical justification to be acceptable. 


\section{CONCLUSIONS}

This paper provided a brief overview of several technical issues identified in the review of DC applications that are related to seismic analysis for new reactors. It is hoped that the insights and discussions provided in this paper will contribute to a better understanding of these issues, thereby improving the analysis and design performed in support of DC and COL applications, and will also facilitate NRC safety reviews.

\section{DISCLAIMER NOTICE}

The findings and opinions expressed in this paper are those of the authors and do not necessarily reflect the views of Brookhaven National Laboratory or the NRC. The paper may present information that does not currently represent an agreedupon NRC position.

\section{REFERENCES}

[1] 10 CFR Part 50. Domestic Licensing of Production and Utilization Facilities. U.S. Nuclear Regulatory Commission, Washington, DC.

[2] NUREG-0800. Standard Review Plan for the Review of Safety Analysis Reports for Nuclear Power Plants: LWR Edition. U.S. Nuclear Regulatory Commission, Washington, DC.

[3] 10 CFR Part 52. Licenses, Certifications, and Approvals for Nuclear Power Plants. U.S. Nuclear Regulatory Commission, Washington, DC.

[4] Xu, J., and Samaddar, S., 2009. "Overview of seismic issues in design certification and combined license application reviews". In Proceedings of the ASME 2009 Pressure Vessels \& Piping Division Conference (PVP2009), July 2630, 2009, Prague, Czech Republic. Paper PVP2009-77322.

[5] 10 CFR Part 100. Reactor Site Criteria. U.S. Nuclear Regulatory Commission, Washington, DC.

[6] Regulatory Guide 1.60, 1973. Design Response Spectra for Seismic Design of Nuclear Power Plants, Revision 1. U.S. Nuclear Regulatory Commission, Washington, DC.

[7] Regulatory Guide 1.208, 2007. A Performance-Based Approach to Define the Site-Specific Earthquake Ground Motion. U.S. Nuclear Regulatory Commission, Washington, DC.

[8] ISG-01, 2009. Interim Staff Guidance on Seismic Issues Associated with High Frequency Ground Motion in Design Certification and Combined License Applications. U.S. Nuclear Regulatory Commission, Washington, DC.

[9] ASCE 4-98, 1999. Seismic Analysis of Safety-Related Nuclear Structures and Commentary. American Society of Civil Engineers, Reston, Va.

[10] ASCE 43-05, 2005. Seismic Design Criteria for Structures,
Systems, and Components in Nuclear Facilities. American Society of Civil Engineers, Reston, Va. 